\title{
CÁC YẾU TỐ ẢNH HƯởNG ĐẾN LÒNG TRUNG THÀNH CỦA NHÂN VIÊN ĐỐI VỚI CÔNG TY TNHH ĐIỆN THÀNH VINH
}

\author{
MAI THANH HÙNG, ĐẶNG TRUNG KIÊN \\ Khoa Thuơng mại \& Du lịch, Truờng Đại Học Công Nghiệp TP. Hồ Chí Minh. \\ maithanhhung@iuh.edu.vn
}

Tóm tắt. Bài báo này nhằm mục đích nhận diện các yếu tố ảnh hưởng đến lòng trung thành của nhân viên công ty TNHH Điện Thành Vinh đối với tổ chức và đưa ra các giải pháp giúp xây dựng lòng trung thành của nhân viên. Dựa trên phương pháp phân tích dữ liệu như phân tích Cronbach's alpha, phân tích EFA và phân tích hồi quy bội từ đó đo lường mức độ ảnh hưởng các yếu tố đến lòng trung thành của nhân viên đối với công ty Điện Thành Vinh.

Các kết quả thu được từ nghiên cứu này góp phần bổ sung vào thực tiễn quản lý, giúp các nhà quản trị hiểu biết rõ hơn về công tác quản trị nguồn nhân lực, tạo được động lực để nâng cao sự trung thành của nhân viên với tổ chức nhằm duy trì nguồn lực cho doanh nghiệp.

Từ khóa: Lòng trung thành của nhân viên, Công ty TNHH Điện Thành Vinh.

\section{FACTORS AFFECTING EMPLOYEES'S LOYALTY FOR THANH VINH ELECTRONIC CO., LTD.}

\begin{abstract}
This article aims to identify factors affecting the loyalty of employees of Dien Vinh Co., Ltd. to the organization and provide solutions to help build employee loyalty. Based on data analysis methods such as Cronbach's alpha analysis, EFA analysis and multiple regression analysis to measure the influence of factors on employee loyalty on Điện Thành Vinh Company.

The results from this study contribute to the management practices, help managers better understand the management of human resources, create motivation to improve employee loyalty. with the organization to maintain resources for the business.
\end{abstract}

Key words: Staff loyalty, Thanh Vinh Electric Co., Ltd.

\section{1. ĐẶT VẤN ĐỀ}

Nhu cầu nguồn nhân lực là rất quan trọng ở bất kỳ mỗi cơ quan tổ chức nào, đặc biệt là trong giai đoạn hiện nay tình hình nhân sự trong ngành thiết bị điện tử thật rất cần thiết, bởi vì thị truờng cạnh tranh với nhau không những bởi sản phẩm dịch vụ mà là bởi yếu tố con người. Nhiều doanh nghiệp trong ngành thiết bị điện tử hiện nay xem con người là tài sản quý giá nhằm thu hút nhân tài từ các đối thủ cạnh tranh và phải làm thế nào để nhân sự công ty gắn bó dài lâu, trung thành với doanh nghiệp để ổn định phát triển là bài toán mà các doanh nghiệp luôn phải giải quyết cấp bách. Hiện nay, các công ty cung cấp thiết bị điện trong và ngoài nước đang đứng trước những thách thức không nhỏ trong việc duy trì và phát triển nguồn nhân lực nội tại. Tuyển dụng là một khía cạnh quan trọng, nhưng giữ được nguồn nhân lực chất lượng cao lại là một vấn đề quan trọng hơn rất nhiều.

Việc thực hiện tốt công tác quản trị nguồn nhân lực sẽ giúp các nhà quản lý duy trì được nguồn nhân lực chất lượng cao tại doanh nghiệp cũng như làm tăng lòng trung thành của nhân viên và hạn chế được việc nhân viên của mình rời bỏ doanh nghiệp. Đây cũng là đề tài được nghiên cứu bởi nhiều chuyên gia trong nước và các nhà nghiên cứu nổi tiếng ở nước ngoài như Các nghiên cứu của Foreman Facts (1946) Schermerhon (1993), Spector (1997), Trần Kim Dung (2005), Vũ Khắc Đạt (2008), Nguyễn Vũ Duy Nhất (2009)... đều chỉ ra rằng nhân tố chính ảnh hưởng đến quá trình và kết quả làm việc của nhân viên chính là lòng trung thành với tổ chức. Các nghiên cứu trên thế giới chỉ ra rằng khi tổ chức thực hiện tốt các công tác quản trị nguồn nhân lực sẽ mang lại hài lòng cho nhân viên và từ đó họ cống hiến và trung thành với tổ chức nhiều hơn.

Tại công ty TNHH Điện Thành Vinh công tác quản trị nguồn nhân lực chưa thực sự được quan tâm nhiều về công tác gắn kết và tạo dựng lòng trung thành của nhân viên đối với công ty còn nhiều hạn chế. Công ty TNHH chuyên hoạt động trong lĩnh vực cung cấp thiết bị điện công nghiệp và gia dụng tại TP.HCM tuy 
nhiên Điện Thành Vinh hiện đang hoạt động trong một thị trường kinh doanh khốc liệt với hàng loạt các doanh nghiệp thiết bị điện lớn như như Schneider, Nhật Minh, Thiên Thành, Tongda...và sắp tới là hàng loạt các doanh nghiệp khu vực Châu Á khác. Trong khi đó, về vấn đề nguồn nhân lực, nhân viên chưa gắn kết lâu, nhiều nhân viên nghỉ việc trong thời gian dài, nguyên do là công tác quản trị nguồn nhân lực chưa tốt, chưa tạo được dựng được lòng tin để nhân viên trung thành với công ty. Cụ thể là tỷ lệ nhân viên nghỉ việc năm 2018 là $35 \%$, chuyển việc sang đơn vị khác là $28 \%$ điều này chứng tỏ sự cam kết và lòng trung thành của nhân viên tại công ty Điện Thành Vinh chưa cao và có nhiều yếu kém trong việc tìm hiểu các yếu tố ảnh hưởng đến lòng trung thành của nhân viên.

Vì thế từ các nghiên cứu trước đây của thế giới và thực tiễn quản trị nhân sự tại công ty Điện Thành Vinh thì bài báo "Các yếu tố ảnh hưởng đến lòng trung thành của nhân viên tại Công ty TNHH Điện Thành Vinh" là cần thiết, giúp ích cho ban lãnh đạo đưa ra những điều chỉnh về cổng tác quản trị nguồn nhân lực. Nghiên cứu này cho chúng ta một số nhận định về các yếu tố ảnh hưởng đển lòng trung thành của nhân viên tại công ty $\mathrm{TNHH}$ Điện Thành Vinh và biết được thành phần nào tác động mạnh nhất đến lòng trung thành của nhân viên. Qua đó, giúp công ty TNHH Điện Thành Vinh có được sự điều chỉnh phù hợp với xu thế phát triển chung và đưa ra một số giải pháp giúp cho các doanh nghiệp có những hành động nâng cao lòng trung thành của nhân viên đổi với doanh nghiệp.

\section{CƠ SỞ LÝ LUẬN VÀ MÔ HÌNH NGHIÊN CÚU}

\subsection{Cơ sở lý luận:}

\subsubsection{Các khái niệm}

Quản trị nguồn nhân lực là hệ thống các triết lý, chính sách và hoạt động chức năng về thu hút, đào tạo phát triển và duy trì con người của một tổ chức nhằm đạt kết quả tối ưu cho cả tổ chức lẫn nhân viên (Trần Kim Dung, 2011).

Bùi Anh Tuấn (2009) định nghĩa rằng con người làm việc trong tổ chức (tổ chức được hiểu theo nghĩa rộng), là nguồn lực quan trọng nhất của tổ chức. Họ làm việc cho tổ chức, vì mục tiêu của tổ chức. Tổ chức tuyển dụng, đào tạo và sử dụng họ, chi phối hành vi của họ. Ngược lại, chính họ là lực lượng quyết định đến sự tồn tại và phát triển của tổ chức.

Bateman và Strasser (1984) định nghĩa lòng trung thành của nhân viên là sự sẵn sàng nỗ lực cho danh nghĩa của tổ chức, cho những mục tiêu và giá trị để phù hợp với tổ chức, và mong muốn được duy trì là thành viên của tổ chức.

Khi định nghĩa về lòng trung thành Allen \& Mayer (1991) chú trọng ba trạng thái tâm lý của nhân viên khi gắn kết với tổ chức. Nhân viên có thể trung thành với tổ chức xuất phát từ tình cảm thật sự của họ: họ sẽ ở lại với tổ chức dù có nơi khác trả lương cao hơn, điều kiện làm việc tốt hơn: họ có thể trung thành với tổ chức chỉ vì họ không có cơ hội kiếm được công việc tốt hơn và họ có thể trung thành với tổ chức vì những chuẩn mực đạo đức mà họ theo đuổi.

\subsubsection{Các lọi ích của việc xây dựng, duy trì lòng trung thành của nhân viên}

Đối với các doanh nghiệp, đặc biệt trong môi trường đầy biến động của các doanh nghiệp thiết bị điện thì việc xây dựng lòng trung thành của nhân viên mang rất nhiều lợi ích có thể thấy rõ sau đây:

- Về mặt doanh thu, khi các nhân viên có lòng trung thành với tổ chức, tương lai được đảm bảo khiến cho họ có khuynh hướng làm việc tốt hơn cả những gì khách hàng mong đợi và luôn có tinh thần làm việc cao ở khả năng tốt nhất của họ. Cả hai đặc điểm này đều rất quan trọng trong việc giữ lại cho công ty những khách hàng trung thành và đem về doanh thu cao.

- Về mặt chi phí, những nhân viên trung thành sẽ ở lại làm việc với công ty lâu dài, nhân viên có kinh nghiệm có khả năng giải quyết vấn đề một cách nhanh chóng. Nếu các nhân viên này nghỉ thì các doanh nghiệp sẽ tốn một phẩn chi phí không nhỏ để có thể đào tạo lại được một nhân viên khác có khả năng thay thế. Vì vậy, nếu quan tâm đến lòng trung thành của những lập trình viên kinh nghiệm này thì vì công ty sẽ tránh được những khỏan chi phí đáng kể cho việc thay thế nhân viên.

\subsection{Các giả thuyết và mô hình nghiên cứu đề xuất}

\subsubsection{Lòng trung thành nhân viên theo các yếu tố thành phần}

Dựa vào cơ sở lý thuyết đã được đề cập ở trên, đồng thời tham khảo các công trình nghiên cứu trước đó của các tác giả Jen Ruei Fu và Jessica Chen (2015); Sayyed Napvi và Sajid Bashir (2008); Magid Igbaria và cộng sự (2008); Trần Thái Hòa (2014); Lê Cảnh Phước (2007); Trần Thị Cẩm Thúy (2011) về lòng trung thành của nhân viên kết hợp với kết quả nghiên cứu định tính trong giai đoạn nghiên cứu sơ bộ bao gồm 
phỏng vấn chuyên gia và thảo luận nhóm, tác giả tập trung nghiên cứu vào các yếu tố thỏa mãn công việc có tác động đến lòng trung thành của lập trình viên như sau: đặc điểm công việc; thu nhập và phúc lợi; điều kiện và môi trường làm việc; cơ hội đào tạo và phát triển; sự công nhận trong công việc làm cơ sở đề xuất mồ hình nghiên cứu; đồng thời đánh giá các đặc điểm cá nhân có ảnh hưởng như thế nào đến lòng trung thành của nhân viên.

Ngoài ra tác giả bổ sung thêm hai yếu tố sự phù hợp của cá nhân với tổ chức; khả năng làm việc nhóm cũng có ảnh hưởng đến sự thỏa mãn trong công việc và có tác động tới lòng trung thành của nhân viên.

Các yếu tố thành phần ảnh hưởng đến lòng trung thành của nhân viên Điện Thành VInh bao gồm:

(1) Đặc điểm, bản chất công việc: Theo Trần Kim Dung (2005) bản chất công việc là những vấn đề liên quan đến những thách thức của công việc, cơ hội để sử dụng các năng lực cá nhân và cảm nhận thú vị khi thực hiện công việc. Quan điểm của Oldham và Hackman (1976) trong nghiên cứu về tạo động lực làm việc cho rằng bản thân công việc có những đặc trưng thiết yếu của nó. Những đặc trưng đó có thể sẽ làm cho bản thân công việc đó tồn tại một động lực nội tại, và người lao động sẽ được kích thích tăng năng suất làm việc tùy theo bản thân mỗi công việc.

(2) Co hội đào tạo và phát triển: Các chương trình huấn luyện được thực hiện làm tăng kỹ năng làm việc và nhận thức của nhân viên, từ đó họ có thể áp dụng vào công việc và chia sẻ chúng cho các nhân viên khác. Trong khi đó, phát triển là một nỗ lực cung cấp cho nhân viên các kỹ năng mà tổ chức sẽ cần trong tương lai. Phát triển kỹ năng có thể bao gồm sự hoàn thiện kỹ năng đọc viết tài liệu, kỹ năng về kỹ thuật, giao tiếp giữa đồng nghiệp và cấp trên, hoặc kỹ năng giải quyết vấn đề trong môi trường làm việc.

(3) Kỹ năng làm việc nhóm: Khả năng làm việc nhóm là khả năng tương tác giữa các thành viên trong một nhóm, nhằm thúc đẩy hiệu quả công việc việc phát triển tiềm năng của tất cả các thành viên. Một mục tiêu lớn thường đòi hỏi nhiều người làm việc với nhau, vì thế làm việc nhóm trở thành một định nghĩa quan trọng trong tổ chức cũng như trong cuộc sống.

(4) Môi trường làm việc: Là những vấn đề liên quan đến cảm nhận của nhân viên về an toàn nơi làm việc: máy móc, trang thiết bị có đảm bảo an toàn. Nếu không phù hợp và không an toàn đến sức khỏe của họ thì họ sẽ nghĩ đến một môi trường làm việc mới.

(5) Quan hệ trong công việc: Là những cảm nhận liên quan đến hành vi, quan hệ đồng nghiệp, quan hệ cấp trên và cấp dưới trong công việc tại nơi làm việc, sự khuyến khích và hỗ trợ của cấp trên để có thể biết được phạm vi trách nhiệm và hoàn cảnh công việc. Quan hệ làm việc tốt nghĩa là nhân viên cảm nhận được rằng họ được sự giúp đỡ của đồng nghiệp và phối hợp trong công việc tốt, điều đó giúp họ tự tin hoàn thành công việc nhiều hơn

(6) Lương, thưởng, chế độ đãi ngộ: Mục tiêu của tiền lương là động lực kích thích cao nhất đối với nhân viên trong việc thực hiện công việc tốt hơn. Khi nhân viên nhận thấy mình được trả lương cao, công bằng thì sẽ làm việc tốt hơn và hài lòng với công việc hiện tại. Ngược lại, nếu nhân viên cảm nhận rằng mình được trả lương thấp và không công bằng thì sẽ có xu hướng nghĩ đển việc rời khỏi công ty để tìm đến một nơi làm việc mới với mức lương cao hơn và công bằng hơn (Trần Thị Trúc Linh, 2007).

(7) Sự công nhận trong công việc: Theo nghiên cứu của Davies (2001, dẫn bởi Janet Cheng Lian Chew, 2004) cho rằng nhân viên có xu hướng ở lại với tổ chức của họ nếu họ cảm thấy năng lực, sự nỗ lực và các hành động đóng góp của họ được công nhận và đánh giá cao. Ngược lại, nếu như những đóng góp của họ không được công nhận và đánh giá cao, họ sẽ có suy nghĩ chuyển tới những công ty khác đánh giá hơn chính xác về sự đóng góp của họ trong công việc.

(8) Sự phù hợp của cá nhân với tổ chức: Là niềm tin của cá nhân với tổ chức hoặc mục tiêu cá nhân với mục tiêu của tồ chức (Cheng và Chew, 2004, được dẫn bởi Võ Quốc Hưng, 2009). Như vậy, những người không phù hợp nhiều với công việc hoặc tổ chức thì có xu hướng thích rời bỏ tổ chức nhiều hơn là những người phù hợp giữa cá nhân với tổ chức.

\subsubsection{Mô hình nghiên cứu đề xuất}

Trên cơ sở phân tích các yếu tố ảnh hưởng đến lòng trung thành của nhân viên với tổ chức ở trên, tác giả đề xuất mô hình nghiên cứu các yếu tố ảnh hưởng đến lòng trung thành của nhân viên tại công ty TNHH Điện Thành Vinh như sau: 


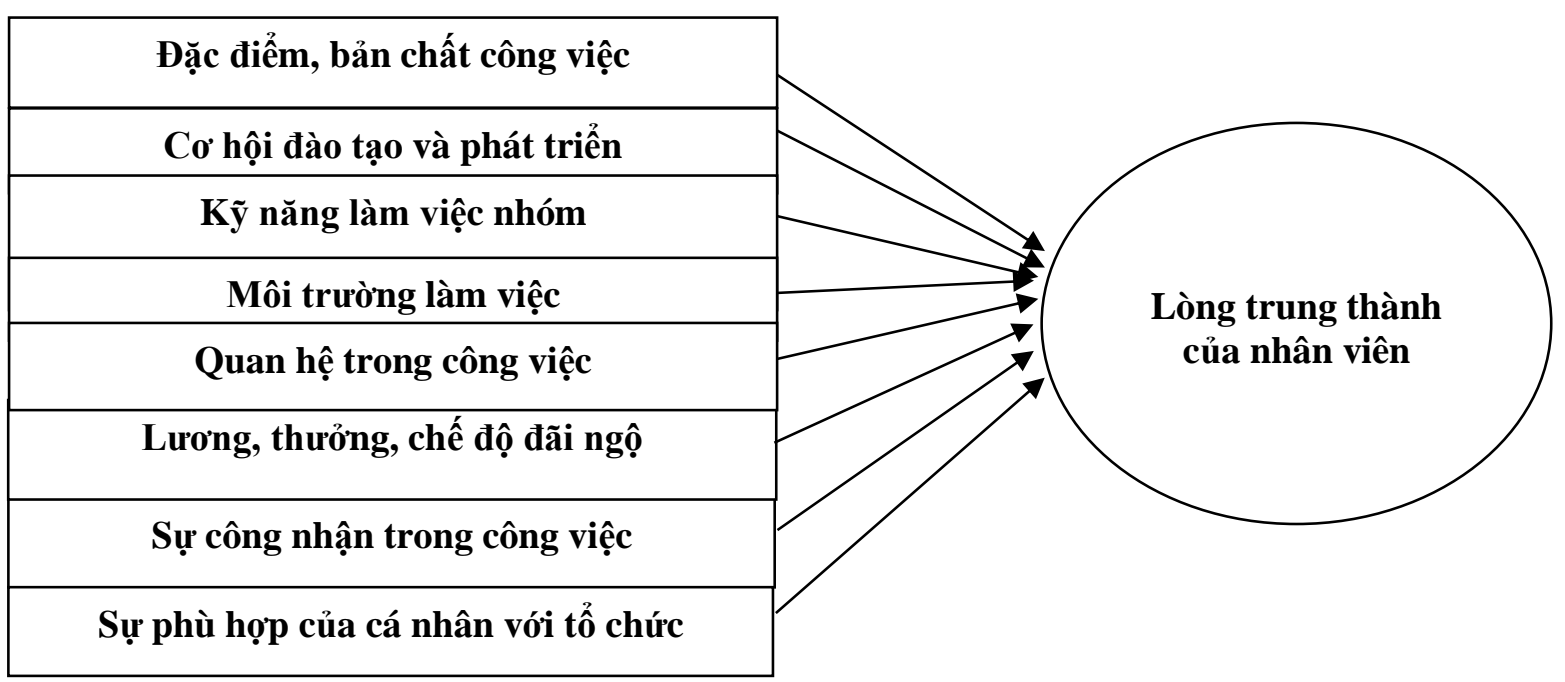

2.2.3 Các giả thuyết nghiên cứu

Hình 1: Mô hình nghiên cứu tác giả đề xuất

- Giả thuyết H1: Đặc điểm, bản chất công việc ảnh hưởng đến lòng trung thành nhân viên.

- Giả thuyết H2: Cơ hội đào tạo và phát triển ảnh hưởng đến lòng trung thành nhân viên.

- Giả thuyết H3: Kỹ năng làm việc nhóm ảnh hưởng đến lòng trung thành nhân viên.

- Giả thuyết H4: Môi trường làm việc ảnh hưởng đến lòng trung thành nhân viên.

- Giả thuyết H5: Quan hệ trong công việc ảnh hưởng đến lòng trung thành nhân viên.

- Giả thuyết H6: Lương, thưởng, chế độ đãi ngộ ảnh hưởng đến lòng trung thành nhân viên.

- Giả thuyết H7: Sự công nhận trong công việc ảnh hưởng đến lòng trung thành nhân viên.

- Giả thuyết H8: Sự phù hợp của cá nhân với tổ chức ảnh hưởng đển lòng trung thành nhân viên.

\section{PHƯƠNG PHÁP NGHIÊN CÚU}

\subsection{Thiết kế nghiên cứu}

Trong giới hạn của một bài báo, các dữ liệu thu thập được xử lý đơn giản, phục vụ cho việc giải thích kết quả. Vì thế phương pháp được lựa chọn là phương pháp phân tích thống kê mô tả. Kỹ thuật xử lý dữ liệu chính được lựa chọn là kỹ thuật phân tích bằng máy tính.

Nghiên cứu được thực hiện gồm hai phương pháp: Phương pháp nghiên cứu định tính và phương pháp nghiên cứu định lượng.

Trong đó, nghiên cứu định tính được thực hiện thông qua kỹ thuật thảo luận nhóm tập trung.

Nghiên cứu định lượng thực hiện bằng kỹ thuật thu thập thông tin trực tiếp bằng phiếu khảo sát trực tiếp đối tượng nghiên cứu. Để tìm hiểu về những yếu tố ảnh hưởng đến sự cam kết của nhân viên tại Công ty Điện Thành Vinh, thang đo các nhân tố ảnh hưởng đến được kiểm định thông qua hệ số tin cậy Cronbach's Alpha, phân tích nhân tố khám phá EFA, thông qua phần mềm xử lý số liệu thống kê SPSS .

\section{Mô tả mẫu nghiên cứu}

Mẫu điều tra được triển khai tại công ty TNHH Điện Thành Vinh thành phố Hồ Chí Minh trong thời gian hai tháng (từ 01/09/2019 đến 01/11/2019). Điện Thành Vinh là công ty thiết bị điện công nghiệp - điện dân dụng được thành lập từ năm 2008. Trải qua quá trình hoạt động và phát triển lâu dài, Điện Thành Vinh hiện tại đang là nhà phân phối các thiết bị và sản phẩm chủ yếu trong lĩnh vực điện dân dụng và điện công nghiệp trên địa bàn thành phố Hồ Chí Minh. Công ty TNHH Điện Thành Vinh chuyên cung cấp các thiết bị điện: Sản phẩm điện dân dụng, thiết bị điện công nghiệp, sản phẩm điện chiếu sáng công nghiệp, các sản phẩm linh kiện điện tử. Tổng số bảng câu hỏi được phát ra để thu thập là 415 bảng. Tuy nhiên số lượng bảng câu hỏi thu về là 406 , tỷ lệ hồi đáp đạt $97,8 \%$. Sau đó, bảng câu hỏi thu thập được sàng lọc và kiểm tra tính hợp lệ cũng như phù hợp với tiêu chuẩn phạm vi nghiên cứu: đảm bảo đầy đủ các thông tin nhân khẩu học của đối tượng khảo sát là nhân viên đang làm việc tại công ty $\mathrm{TNHH}$ Thành Vinh trong thời gian từ 01/09/2019 đển 01/11/2019 thì số lượng bảng câu hỏi còn lại được đưa vào xử lý là 400 bảng (chiếm 98,5\% mẫu thu thập được). 
Bảng 1: Bảng mô tả mẫu nghiên cứu

\begin{tabular}{|c|c|c|c|c|}
\hline & ng tin mẫu & Tần số & Tỷ lệ \% & \% tích lũy \\
\hline \multicolumn{5}{|l|}{ Giới tính } \\
\hline & Nam & 268 & 67 & 67 \\
\hline & Nữ & 132 & 33 & 100 \\
\hline \multicolumn{5}{|l|}{ Độ tuổi } \\
\hline & Từ 21-29 tuổi & 61 & 15,3 & 15,3 \\
\hline & Từ 30-39 tuổi & 320 & 80 & 95,3 \\
\hline & Từ 40-49 tuổi & 13 & 3,3 & 98,5 \\
\hline & Trên 50 tuổi & 6 & 1,5 & 100 \\
\hline \multicolumn{5}{|c|}{ Trình độ học vấn } \\
\hline & Trung cấp & 20 & 5 & 5 \\
\hline & Cao Đằng & 63 & 15,8 & 20,8 \\
\hline & Đại Học & 178 & 44,5 & 65,3 \\
\hline & Sau Đại Học & 135 & 33,8 & 99 \\
\hline & Tiến Sĩ & 4 & 1 & 100 \\
\hline \multicolumn{5}{|c|}{ Tình trạng hôn nhân } \\
\hline & Có gia đình & 234 & 58,5 & 58,5 \\
\hline & Độc thân & 166 & 41,5 & 100 \\
\hline \multicolumn{5}{|c|}{ Thâm niên công tác } \\
\hline & Dưới 2 năm & 87 & 21,8 & 21,8 \\
\hline & Từ 2 đến dưới 3 năm & 82 & 20,5 & 42,3 \\
\hline & Từ 3 đến dưới 5 năm & 172 & 43 & 85,3 \\
\hline & Từ 5 đến dưới 7 năm & 36 & 9 & 94,3 \\
\hline & Từ 7 năm trở lên & 23 & 5,8 & 100 \\
\hline
\end{tabular}

\subsection{Thiết kế thang đo}

Nguồn: Số liệu phân tích dũ liệu nghiên cứu chính thức bằng SPSS 23.0 của tác giả

\subsubsection{Thiết kế thang đo cho bảng câu hỏi}

Thang đo được sử dụng là thang đo Likert gồm 5 mức độ như sau: Rất không đồng ý, Không đồng ý, Không có ý kiến, Đồng ý, Hoàn toàn đồng ý.

Nội dung các biến quan sát trong các thành phần được hiệu chỉnh cho phù hợp với tình hình nhân sự thực tế tại công ty TNHH Điện Thành Vinh tại Thành phố Hồ Chí Minh.

\subsubsection{Diễn đạt và mã hóa thang đo}

Dựa trên các cồng trình nghiên cứu trong và ngoài nước trước đó như công trình nghiên cứu về đặc điểm côngviệc của Magid Ibaria (1994), chế độ đãi ngộ và hành vi lãnh đạo trong nghiên cứu của Sayyed (2008) cùng một số biến quan sát bổ sung phù hợp với tình hình tại công ty TNHH Điện Thành Vinh tại Thành phố Hồ Chí Minh, tác giả đưa ra thang đo nghiên cứu bao gồm các thành phần độc lập và phụ thuộc được mã hóa như sau:

Bảng 2: Bảng mô tả thang đo các yếu tố thành phần độc lập và phụ thuộc

\begin{tabular}{|l|l|c|c|}
\hline \multicolumn{1}{|c|}{ THANG ĐO GỐC } & \multicolumn{1}{|c|}{ THANG ĐO ĐIÊU CHÎNH } & NGUỒN & $\begin{array}{c}\text { MÁ } \\
\text { HÓA }\end{array}$ \\
\hline \multicolumn{3}{|c|}{ Thang đo thành phần đặc điểm, bản chất công việc } \\
\hline $\begin{array}{l}\text { Tôi cảm nhận mạnh mẽ về sự thú vị } \\
\text { ngành nghề trong công việc của mình. }\end{array}$ & $\begin{array}{l}\text { Bạn nhận thấy công việc của bạn rất } \\
\text { thú vị. }\end{array}$ & $\begin{array}{c}\text { Fu và Chen } \\
(2015)\end{array}$ & CV1 \\
\cline { 1 - 2 } $\begin{array}{l}\text { Tôi cảm thấy hài lòng với những tiến bộ } \\
\text { trong năng lực của mình để đạt được } \\
\text { những mục tiêu trong công việc. }\end{array}$ & $\begin{array}{l}\text { Công việc tại công ty giúp bạn phát } \\
\text { huy tối đa được năng lực cá nhân. }\end{array}$ & & CV2 \\
\hline
\end{tabular}


TNHH ĐIỆN THÀNH VINH

\begin{tabular}{|c|c|c|c|}
\hline Công việc có nhiều thách thức. & $\begin{array}{l}\text { Công việc có nhiều thách thức khiến } \\
\text { bạn muốn chinh phục. }\end{array}$ & $\begin{array}{c}\text { Hackman } \\
\text { \& Oldham } \\
(1976)\end{array}$ & $\mathrm{CV} 3$ \\
\hline $\begin{array}{l}\text { Tôi không phải gác lại những việc khác } \\
\text { trong cuộc sống của mình để dành thời } \\
\text { gian cho công viêc. }\end{array}$ & $\begin{array}{l}\text { Công việc không đòi hỏi thường } \\
\text { xuyên phải làm việc ngoài giờ. }\end{array}$ & $\begin{array}{l}\text { Fu và Chen } \\
\text { (2015) }\end{array}$ & CV4 \\
\hline & $\begin{array}{l}\text { Bạn tự hào khi nói về công việc của } \\
\text { mình. }\end{array}$ & $\begin{array}{c}\text { Tác giả đề } \\
\text { xuất }\end{array}$ & CV5 \\
\hline \multicolumn{4}{|c|}{ Thang đo thành phần lương, thưởng và chế độ đãi ngộ } \\
\hline Tổ chức/công ty có chế độ phúc lợi tốt. & $\begin{array}{l}\text { Công ty có chế độ phúc lợi tốt hơn } \\
\text { các công ty khác. }\end{array}$ & \multirow[t]{2}{*}{$\begin{array}{l}\text { Fu và Chen } \\
\quad(2015)\end{array}$} & LTC1 \\
\hline $\begin{array}{l}\text { Tôi hài lòng với mức lương mà doanh } \\
\text { nghiệp trả cho tôi. }\end{array}$ & $\begin{array}{l}\text { Mức lương hiện tại của bạn được trả } \\
\text { tương xứng với năng lực và đóng góp } \\
\text { cho công ty }\end{array}$ & & LTC2 \\
\hline $\begin{array}{l}\text { Anh/Chị có thể sống hoàn toàn dựa vào } \\
\text { thu nhập từ tồ chức/ công ty }\end{array}$ & $\begin{array}{l}\text { Mức lương hiện tại đảm bảo cho cuộc } \\
\text { sông cá nhân và gia đình của bạn. }\end{array}$ & $\begin{array}{l}\text { Trần Thái } \\
\text { Hòa (2014) }\end{array}$ & LTC3 \\
\hline $\begin{array}{l}\text { Tôi được khen thưởng công bằng dựa } \\
\text { trên tinh thần trách nhiệm bản thân. }\end{array}$ & $\begin{array}{l}\text { Sự khen thưởng là xứng đáng dựa } \\
\text { trên trách nhiệm công việc của bạn }\end{array}$ & \multirow[t]{2}{*}{$\begin{array}{l}\text { Fu và Chen } \\
\text { (2015) }\end{array}$} & LTC4 \\
\hline $\begin{array}{l}\text { Tôi được khen thưởng công bằng dựa } \\
\text { trên mức độ mệt mỏi và căng thằng } \\
\text { trong quá trình làm việc. }\end{array}$ & $\begin{array}{l}\text { Sự khen thưởng dành của bạn được } \\
\text { đánh giá công bằng dựa trên sự hao } \\
\text { hưt về sức lao động (sức lực và trí } \\
\text { lực) khi bạn cống hiến cho công việc. }\end{array}$ & & LTC5 \\
\hline \multicolumn{4}{|c|}{ Thang đo thành phần khả năng làm việc theo nhóm } \\
\hline $\begin{array}{l}\text { Mọi thành viên trong nhóm đều có thể } \\
\text { đưa ra ý kiến của mình. }\end{array}$ & $\begin{array}{l}\text { Bạn cho rằng khi làm việc trong } \\
\text { nhóm, bạn có thể bày tỏ ý kiến của } \\
\text { mình và được chấp nhận. }\end{array}$ & \multirow[t]{3}{*}{$\begin{array}{l}\text { Kee Hui } \\
\text { Po \& cộng } \\
\text { sự (2012) }\end{array}$} & LVN1 \\
\hline $\begin{array}{l}\text { Tôi sẵn sang đưa ra ý kiến của mình và } \\
\text { thảo luận với các đồng nghiệp. }\end{array}$ & $\begin{array}{l}\text { Ý kiến bạn đưa ra luôn có giá trị và } \\
\text { được các thành viên khác đánh giá } \\
\text { cao. }\end{array}$ & & LVN2 \\
\hline $\begin{array}{l}\text { Thành viên trong nhóm luôn có được } \\
\text { những thông tin cần thiết để hoàn thành } \\
\text { tốt công việc của mình. }\end{array}$ & $\begin{array}{l}\text { Giữ nguyên biến quan sát của thang } \\
\text { đo gốc. }\end{array}$ & & LVN3 \\
\hline $\begin{array}{l}\text { Khi nhóm đang gặp vấn đề, các thành } \\
\text { viên trong nhóm thực sự nghiêm túc } \\
\text { trong việc tìm hiểu nguyên nhân xảy ra. }\end{array}$ & $\begin{array}{l}\text { Bạn đánh giá nhóm làm việc của } \\
\text { mình thực sự nghiêm túc mối khi gặp } \\
\text { vấn đề trong công việc. }\end{array}$ & \multirow[t]{2}{*}{$\begin{array}{l}\text { Kee Hui } \\
\text { Po \& cộng } \\
\text { sự (2012) }\end{array}$} & LVN4 \\
\hline $\begin{array}{l}\text { Mọi thành viên trong nhóm đều nhận } \\
\text { thức được sự đóng góp của bản thân vào } \\
\text { thành công của nhóm. }\end{array}$ & $\begin{array}{l}\text { Bạn nhận thức được sự đóng góp của } \\
\text { bản thân vào thành công của nhóm. }\end{array}$ & & LVN5 \\
\hline \multicolumn{4}{|c|}{ Thang đo thành phần môi trường làm việc } \\
\hline Nơi làm việc sạch sẽ, thoáng mát & $\begin{array}{l}\text { Nơi làm việc của bạn rất sạch sẽ, } \\
\text { thoáng mát và đủ ánh sáng }\end{array}$ & \multirow[t]{4}{*}{$\begin{array}{l}\text { Trần Thái } \\
\text { Hòa (2014) }\end{array}$} & MT1 \\
\hline $\begin{array}{l}\text { Được cung cấp đầy đủ các dụng cụ làm } \\
\text { việc. }\end{array}$ & $\begin{array}{l}\text { Bạn được cung cấp đầy đủ các vật } \\
\text { dụng cá nhân, trang thiết bị phù hợp } \\
\text { với công việc. }\end{array}$ & & MT2 \\
\hline Nơi làm việc an toàn. & $\begin{array}{l}\text { Bạn cảm nhận được nơi làm việc của } \\
\text { mình rất an toàn }\end{array}$ & & MT3 \\
\hline Thời gian làm việc thích hợp. & $\begin{array}{l}\text { Thời gian làm việc của công ty linh } \\
\text { hoạt, phù hợp với bạn. }\end{array}$ & & MT4 \\
\hline \multicolumn{4}{|c|}{ Thang đo thành phần cơ hội đào tạo và phát triển } \\
\hline $\begin{array}{l}\text { Tổ chức cung cấp cho tôi các huấn } \\
\text { luyện liên quan đến công việc. }\end{array}$ & $\begin{array}{l}\text { Bạn được định hướng và huấn luyện } \\
\text { phù hợp với công việc đảm nhận. }\end{array}$ & $\begin{array}{l}\text { Naqvi } \\
(2011)\end{array}$ & DT1 \\
\hline
\end{tabular}




\begin{tabular}{|c|c|c|c|}
\hline $\begin{array}{l}\text { Có nhiều cơ hội phát triển dành cho tôi } \\
\text { trong tổ chức. }\end{array}$ & $\begin{array}{l}\text { Công ty tạo điều kiện cho bạn thăng } \\
\text { tiến và phát triển kỹ năng nghề } \\
\text { nghiệp. }\end{array}$ & & DT2 \\
\hline $\begin{array}{l}\text { Sự đổi mới/sáng tạo luôn được khuyến } \\
\text { khích }\end{array}$ & $\begin{array}{l}\text { Bạn cảm nhận được công ty khuyến } \\
\text { khích sự đồi mới/ sáng tạo trong } \\
\text { công việc. }\end{array}$ & & DT3 \\
\hline $\begin{array}{l}\text { Tôi được cơ hội tham gia các hoạt động } \\
\text { có tác động tới phát triển nghề nghiệp. }\end{array}$ & $\begin{array}{l}\text { Công ty cho bạn cơ hội được đào tạo, } \\
\text { cung cấp kiến thức/ kỹ năng cần thiết } \\
\text { cho công việc của bạn }\end{array}$ & & DT4 \\
\hline $\begin{array}{l}\text { Các chương trình đào tạo và phát triển } \\
\text { nghề nghiệp tại công ty hiện nay phù } \\
\text { hợp về thời gian. }\end{array}$ & $\begin{array}{l}\text { Các chương trình đào tạo và phát } \\
\text { triển nghề nghiệp tại công ty là rât tốt, } \\
\text { phù hợp thời gian với nhân viên. }\end{array}$ & & DT5 \\
\hline \multicolumn{4}{|c|}{ Thang đo thành phần quan hệ trong công việc } \\
\hline Đồng nghiệp đáng tin cậy và trung thực & $\begin{array}{l}\text { Bạn cảm nhận đồng nghiệp của bạn } \\
\text { đáng tin cây và trung thực }\end{array}$ & \multirow[t]{5}{*}{$\begin{array}{l}\text { Trần Thái } \\
\text { Hòa (2014) }\end{array}$} & DN1 \\
\hline $\begin{array}{l}\text { Đồng nghiệp phối hợp làm việc tốt với } \\
\text { nhau }\end{array}$ & $\begin{array}{l}\text { Đồng nghiệp ở công ty có sự phối } \\
\text { hợp, làm việc tốt với nhau. }\end{array}$ & & DN2 \\
\hline $\begin{array}{l}\text { Đồng nghiệp thường san sẻ công việc và } \\
\text { giúp đỡ nhau trong cuộc sống. }\end{array}$ & $\begin{array}{l}\text { Đồng nghiệp của bạn thường san sẻ } \\
\text { công việc và giúp đỡ nhau trong cuộc } \\
\text { sống. }\end{array}$ & & DN3 \\
\hline $\begin{array}{l}\text { Đồng nghiệp thoải mái, vui vẻ, hòa } \\
\text { đồng. }\end{array}$ & Giữ nguyên thang đo gốc & & DN4 \\
\hline $\begin{array}{l}\text { Đồng nghiệp biết hợp tác làm } \\
\text { việc nhóm. }\end{array}$ & $\begin{array}{l}\text { Đồng nghiệp công ty bạn biết hợp tác } \\
\text { làm việc nhóm }\end{array}$ & & DN5 \\
\hline $\begin{array}{l}\text { Họ luôn nhấn mạnh tầm quan trọng } \\
\text { trong việc Anh/Chị có cùng sứ mạng với } \\
\text { tổ chức. }\end{array}$ & $\begin{array}{l}\text { Bạn được lãnh đạo trong công ty tôn } \\
\text { trọng và tin cậy. }\end{array}$ & \multirow[t]{2}{*}{$\begin{array}{l}\text { Trần Thị } \\
\text { Cẩm Thúy } \\
\text { (2011) }\end{array}$} & DN6 \\
\hline Họ luôn hướng dẫn, tư vấn cho Anh/Chị & $\begin{array}{l}\text { Bạn được lãnh đạo công ty tư vấn, } \\
\text { hướng dẫn và giúp đỡ khi cần thiết để } \\
\text { giải quyết vấn đề cá nhân, công việc. }\end{array}$ & & DN7 \\
\hline \multicolumn{4}{|c|}{ Thang đo thành phần sự công nhận trong công việc } \\
\hline $\begin{array}{l}\text { Các đánh giá chính xác, đầy đủ dựa trên } \\
\text { những nỗ lực của tôi. }\end{array}$ & $\begin{array}{l}\text { Công ty đánh giá thành tích của nhân } \\
\text { viên chính xác, kịp thời và đầy đủ. }\end{array}$ & \multirow[t]{4}{*}{$\begin{array}{l}\text { Jen Ruei } \\
\text { Fu (2015) }\end{array}$} & $\mathrm{CN} 1$ \\
\hline $\begin{array}{l}\text { Tôi được khen thưởng công bằng và } \\
\text { xứng đáng cho những cố gắng, áp lực } \\
\text { của ngành nghề. }\end{array}$ & $\begin{array}{l}\text { Các lập trình viên được đánh giá công } \\
\text { việc một cách công bằng. }\end{array}$ & & $\mathrm{CN} 2$ \\
\hline $\begin{array}{l}\text { Tôi được thưởng xứng đáng dựa trên } \\
\text { trách nhiệm, khả năng của mình. }\end{array}$ & $\begin{array}{l}\text { Các tiêu chí để đánh giá năng lực lập } \\
\text { trình viên là hợp lý, rõ rang. }\end{array}$ & & $\mathrm{CN} 3$ \\
\hline \multirow[t]{2}{*}{$\begin{array}{l}\text { Tôi được thường xứng đáng dựa theo } \\
\text { năng lực làm việc tốt. }\end{array}$} & $\begin{array}{l}\text { Kết quả đánh giá là cơ sở cho việc } \\
\text { tuyên } \\
\text { dương, khen thưởng }\end{array}$ & & CN4 \\
\hline & $\begin{array}{l}\text { Bạn cảm thấy các đóng góp của mình } \\
\text { được ghi nhận cho sự phát triển của } \\
\text { công ty }\end{array}$ & $\begin{array}{l}\text { Tác giả đề } \\
\text { xuất }\end{array}$ & CN5 \\
\hline \multicolumn{4}{|c|}{ Thang đo thành phần sư phù hợp của cá nhân đối với tổ chức } \\
\hline Nhân viên yêu thích văn hóa công ty. & Bạn yêu thích văn hóa công ty. & \multirow{3}{*}{$\begin{array}{l}\text { Trần Thái } \\
\text { Hòa (2014) }\end{array}$} & PH1 \\
\hline $\begin{array}{l}\text { Công ty có chiến lược phát triển bền } \\
\text { vững. }\end{array}$ & $\begin{array}{l}\text { Bạn cảm nhận được công ty có chiến } \\
\text { lược phát triển bền vững. }\end{array}$ & & $\mathrm{PH} 2$ \\
\hline Nhân viên thấy văn hóa công ty phù hợp & $\begin{array}{l}\text { Bạn cho rằng văn hóa công ty là phù } \\
\text { hợp. }\end{array}$ & & PH3 \\
\hline
\end{tabular}


TNHH ĐIỆN THÀNH VINH

\begin{tabular}{|l|l|c|c|}
\hline Công ty luôn tạo ra sản phẩm có chất & Giữ nguyên thang đo gốc & PH4 \\
\hline \multicolumn{2}{|c|}{ Tha̛ơng cao }
\end{tabular}

\section{KÊT QUẢ NGHIÊN CÚUU}

4.1 Kết quả phân tích độ tin cậy của thang đo

Bảng 3: Kết quả phân tích hệ số Cronbach's Alpha

\begin{tabular}{|c|c|c|c|c|c|}
\hline $\begin{array}{l}\text { Thang đo } \\
\text { thành phần }\end{array}$ & $\begin{array}{l}\text { Số biến } \\
\text { quan sát } \\
\text { ban đầu }\end{array}$ & $\begin{array}{c}\text { Hệ số } \\
\text { Cronbach's } \\
\text { Alpha }\end{array}$ & $\begin{array}{c}\text { Hệ số tương } \\
\text { quan biến } \\
\text { tổng }\end{array}$ & $\begin{array}{c}\text { Hệ số } \\
\text { Cronbach's } \\
\text { Alpha nếu } \\
\text { loai biến }\end{array}$ & $\begin{array}{l}\text { Số biến } \\
\text { quan sát } \\
\text { còn lại }\end{array}$ \\
\hline Đặc điểm, bản chất công việc & 5 & 0,822 & $\geq 0,566$ & $\leq 0,774$ & 5 \\
\hline Co hộ đào tạo và phát triển & 5 & 0,741 & $\geq 0,446$ & $\leq 0,661$ & 5 \\
\hline Kũ năng làm việc nhóm & 5 & 0,945 & $\geq 0,804$ & $\leq 0,922$ & 5 \\
\hline Môi trương làm việc & 4 & 0,776 & $\geq 0,534$ & $\leq 0,664$ & 4 \\
\hline Quan hệ trong công viẹc & 7 & 0,930 & $\geq 0,660$ & $\leq 0,912$ & 7 \\
\hline $\begin{array}{l}\text { Lương, thương, chế độ đãi } \\
\text { ngộ }\end{array}$ & 5 & 0,902 & $\geq 0,671$ & $\leq 0,860$ & 5 \\
\hline Sự công nhận trong công viẹc & 5 & 0,949 & $\geq 0,832$ & $\leq 0,930$ & 5 \\
\hline $\begin{array}{l}\text { Sự phù hơp của cá nhân với } \\
\text { tồ chức }\end{array}$ & 5 & 0,948 & $\geq 0,831$ & $\leq 0,933$ & 5 \\
\hline $\begin{array}{l}\text { Lòng trung thành của nhân } \\
\text { viên }\end{array}$ & 5 & 0,800 & $\geq 0,533$ & $\leq 0,746$ & 5 \\
\hline
\end{tabular}

Nguồn: Số liệu phân tích dũ liệu nghiên cứu chính thức bằng SPSS 23.0 của tác giả

Kết quả ở bảng 3 cho thấy, các thang đo sau khi loại các biến không đạt yêu cầu đều có hệ số tin cậy Cronbach's Alpha lớn hơn 0,6 . Hệ số tương quan biến tổng của các biến quan sát đều lớn hơn 0,3 . Hệ số Cronbach's Alpha nếu loại biến đều đạt tiêu chuẩn tức là bé hơn hệ số Cronbach's Alpha của thang đo. Vì vậy 40 biến quan sát thuộc thang đo các thành phần và 5 biến quan sát thuộc thang đo lòng trung thành của nhân viên với tổ chức đều đạt độ tin cậy.

\subsection{Kết quả phân tích nhân tố khám phá (EFA)}

Bảng 4: Bảng kết quả phân tích nhân tố khám phá của thang đo thực tiễn quản trị nguồn nhân lực 


\begin{tabular}{|c|c|c|c|c|c|c|c|c|c|}
\hline \multirow[t]{2}{*}{ Yếu tố } & \multirow[t]{2}{*}{\begin{tabular}{|c|} 
Biến \\
quan sát
\end{tabular}} & \multicolumn{7}{|c|}{ Nhân tố } & \\
\hline & & 1 & 2 & 3 & 4 & 5 & 6 & 7 & \\
\hline \multirow[t]{7}{*}{ Quan hệ trong công viẹc (DN) } & DN5 & .884 & & & & & & & \\
\hline & DN7 & .883 & & & & & & & \\
\hline & DN4 & .883 & & & & & & & \\
\hline & DN1 & .812 & & & & & & & \\
\hline & DN6 & .801 & & & & & & & \\
\hline & DN3 & .623 & & & & & & & \\
\hline & $\mathrm{DN} 2$ & .612 & & & & & & & \\
\hline \multirow{5}{*}{$\begin{array}{l}\text { Sứ phù hơp của cá nhân đối } \\
\text { với tố chức (PH) }\end{array}$} & PH5 & & .897 & & & & & & \\
\hline & $\mathrm{PH} 2$ & & .894 & & & & & & \\
\hline & PH1 & & .892 & & & & & & \\
\hline & $\mathrm{PH} 4$ & & .880 & & & & & & \\
\hline & $\mathrm{PH} 3$ & & .852 & & & & & & \\
\hline \multirow{5}{*}{$\begin{array}{l}\text { Sự công nhận trong công việc } \\
(C N)\end{array}$} & CN1 & & & .892 & & & & & \\
\hline & $\mathrm{CN} 2$ & & & .867 & & & & & \\
\hline & CN3 & & & .866 & & & & & \\
\hline & CN4 & & & .855 & & & & & \\
\hline & CN5 & & & .854 & & & & & \\
\hline \multirow{5}{*}{$\begin{array}{l}\text { Khả năng làm việc theo nhóm } \\
(L V N)\end{array}$} & LVN1 & & & & .906 & & & & \\
\hline & LVN4 & & & & .875 & & & & \\
\hline & LVN3 & & & & .865 & & & & \\
\hline & LVN2 & & & & .862 & & & & \\
\hline & LVN5 & & & & .826 & & & & \\
\hline \multirow{5}{*}{$\begin{array}{l}\text { Lương, thưởng và chế độ đãi } \\
\text { ngộ (LTC) }\end{array}$} & LTC4 & & & & & .887 & & & \\
\hline & LTC5 & & & & & .865 & & & \\
\hline & LTC2 & & & & & .815 & & & \\
\hline & LTC3 & & & & & .773 & & & \\
\hline & LTC1 & & & & & .742 & & & \\
\hline \multirow{5}{*}{$\begin{array}{l}\text { Đặc điểm, bản chất công việc } \\
(C V)\end{array}$} & CV1 & & & & & & .798 & & \\
\hline & CV5 & & & & & & .694 & & \\
\hline & CV2 & & & & & & .624 & & \\
\hline & CV4 & & & & & & .593 & & \\
\hline & CV3 & & & & & & .549 & & \\
\hline \multirow{5}{*}{$\begin{array}{l}\text { Co hội đào tạo và phát triển } \\
\text { (DT) }\end{array}$} & DT1 & & & & & & & .761 & \\
\hline & DT3 & & & & & & & .685 & \\
\hline & DT2 & & & & & & & .618 & \\
\hline & DT5 & & & & & & & .594 & \\
\hline & DT4 & & & & & & & .591 & \\
\hline Môi truờng làm việc (MT) & MT2 & & & & & & & & .760 \\
\hline
\end{tabular}



TNHH ĐIỆN THÀNH VINH

\begin{tabular}{|l|l|l|l|l|l|l|l|l|}
\hline & MT1 & & & & & & & .743 \\
\hline & MT3 & & & & & & & .606 \\
\hline & MT4 & & & & & & .599 \\
\hline Tổng phương sai trích & & & & \\
\hline Hệ số KMO (kiểm dịnh Barlett) & 0,908 & & \\
\hline Múc ý nghía (Sig.) & 0,000 & \\
\hline
\end{tabular}

Nguồn: Số liệu phân tích dũ liệu nghiên cứu chinh thí̛c bằng SPSS 23.0 của tác giả Kết quả cho thấy, có 7 yếu tố được trích ra đúng như mong đợi của nghiên cứu, tất cả 26 biến quan sát đều có hệ số tải nhân tố lớn hơn tiêu chuẩn cho phép (Factor Loading $>0,5$ ). Đồng thời kiểm định Bartlett cho thấy giữa các biến trong tổng thể có mối tương quan với nhau (mức ý nghĩa sig $=0,000<0,05$ ) với hệ số $\mathrm{KMO}=0,908(0,5<\mathrm{KMO}<1)$. Tổng phương sai trích là $71,392 \%>50 \%$ có nghĩa là giải thích được $71,392 \%$ sự biến thiên của dữ liệu.

Bảng 5: Kết quả phân tích EFA đối với thang đo cam kết tình cảm

\begin{tabular}{|l|l|l|}
\hline \multirow{4}{*}{ Yếu tố } & Biến quan sát & Yếu tố \\
\hline \multirow{3}{*}{ Tông trung thành của nhân viên } & TT1 & 0,797 \\
\cline { 2 - 3 } & TT2 & 0,791 \\
\cline { 2 - 3 } & TT3 & 0,723 \\
\hline & TT4 & 0,709 \\
\hline Tổng phương sai trích & TT5 & 0,708 \\
\hline Hệ số KMO (kiếm định Barlett) & 55,768 \\
\hline Mức ý nghĩa (Sig.) & 0,756 \\
\hline
\end{tabular}

Nguồn: Số liệu phân tích dũ liệu nghiên cứu chính thức bằng SPSS 23.0 của tác giả Kết quả cho thấy, tất cả 4 biến quan sát đều có hệ số tải nhân tố lớn hơn tiêu chuẩn cho phép (Factor loading $>0,5)$. Đồng thời kiểm định Bartlett cho thấy giữa các biến trong tổng thể có mối tương quan với nhau (mức ý nghĩa sig $=0,000<0,05)$ với hệ số $\mathrm{KMO}=0,756(0,5<\mathrm{KMO}<1$ ). Tổng phương sai trích là 55,768 có nghĩa là giải thích được $55,768 \%$ sự biến thiên của dữ liệu.

4.3 Kết quả phân tích hồi qui và kiểm định giả thuyết

Thống kê $F=90,676$ được tính từ $\mathrm{R}^{2}$ có giá trị Sig rất nhỏ $(\mathrm{Sig} .=0,000)$ chứng tỏ mô hình hồi quy là phù hợp. Cả 8 biến số góp phần giải thích $65 \%$ sự biến động của cam kết tình cảm cán bộ nhân viên. Các hệ số VIF đều dưới 2,0; điều này chứng tỏ sự cộng tuyến giữa các biến độc lập là rất thấp, phù hợp với giả định trong nghiên cứu này là các biến số là độc lập với nhau.

Bảng 6: Kết quả phân tích mô hình hồi qui

\begin{tabular}{|c|c|c|c|c|c|c|c|c|}
\hline & \multirow[b]{2}{*}{ Mô hình } & \multicolumn{2}{|c|}{$\begin{array}{l}\text { Hệ số hồi quy chưa } \\
\text { chuẩn hóa }\end{array}$} & \multirow{2}{*}{$\begin{array}{l}\text { Hệ số hồi quy } \\
\text { đã chuẩn hóa } \\
\text { Beta }\end{array}$} & \multirow[b]{2}{*}{$\mathbf{T}$} & \multirow[b]{2}{*}{ Sig. } & \multicolumn{2}{|c|}{ Thống kê đa cộng tuyến } \\
\hline & & B & Std. Error & & & & Tolerance & VIF \\
\hline \multirow[t]{9}{*}{1} & (Constant) &,- 226 &, 145 &, 133 & $-1,558$ &, 120 & & \\
\hline & $\mathrm{CV}$ &, 121 & ,038 & ,077 & 3,206 & ,001 & ,518 & 1,932 \\
\hline & LTC & ,061 & ,027 &, 179 & 2,273 & ,024 & ,789 & 1,268 \\
\hline & LVN &, 133 &, 025 & 150 & 5,253 & 000 &, 775 & 1,290 \\
\hline & MT &, 140 & ,037 & ,158 & 3,807 & ,000 & ,579 & 1,727 \\
\hline & DT &, 168 &, 038 &, 137 & 4,426 & ,000 & ,702 & 1,425 \\
\hline & DN &, 115 &, 032 &, 245 & 3,645 & 000 & ,638 & 1,566 \\
\hline & $\mathrm{CN}$ & ,197 & ,028 & ,245 & 7,133 & ,000 & ,756 & 1,322 \\
\hline & PH &, 130 & ,026 &, 161 & 4,926 & ,000 & ,836 & 1,197 \\
\hline
\end{tabular}

Biến số phu thuộc: lòng trung thành, $R^{2}$ điều chỉnh= 0,650; $F($ Sig $)=90,676(0.000)$

Nguồn: Số liệu phân tích dũ liệu nghiên cưuu chính thức bằng SPSS 23.0 của tác giả 
Kết quả trên cho thấy mức ý nghĩa Sig. của các thành phần là: Bản chất công việc $(\mathrm{CV})$; Lương, thưởng và chế độ đãi ngộ (LTC); Khả năng làm việc theo nhóm (LVN); Môi trường làm việc (MT); Cơ hội đào tạo và phát triển $(\mathrm{DT})$; Quan hệ trong công việc $(\mathrm{DN})$; Sự công nhận trong công việc $(\mathrm{CN})$; Sự phù hợp của cá nhân đối với tổ chức $(\mathrm{PH})$ là đạt yêu cầu vì có hệ số Sig. $<0,05$, do đó các biến trên có ảnh hưởng đến sự cam kết tình cảm của nhân viên. Từ đó tác giả kết luận rằng các giả thuyết $\mathrm{H} 1, \mathrm{H} 2, \mathrm{H} 3, \mathrm{H} 4, \mathrm{H} 5, \mathrm{H} 6, \mathrm{H} 7$, H8 được chấp nhận.

\subsection{Phương trình hồi quy tuyến tính bội}

Phương trình hồi quy tuyến tính dưới sự tác động của 08 yếu tố ảnh hưởng đến lòng trung thành của nhân viên như sau:

TT $=0,121 * C V+0,061 * L T C+0,133 * L V N+0,140 * M T+0,168 * D T+0,115 * D N+0,197 * C N+$ $\mathbf{0 , 1 3 0} * \mathbf{P H}(\mathbf{1})$

Trong đó:

+ Biển phụ thuộc TT: Lòng trung thành của lập trình viên

+ Các biến độc lập: Đặc điểm, bản chất công việc (CV); Lương, thưởng và chế độ đãi ngộ (LTC); Khả năng làm việc theo nhóm (LVN); Môi trường làm việc (MT); Cơ hội đào tạo và phát triển (DT); Quan hệ trong công việc $(\mathrm{DN})$; Sự công nhận trong công việc $(\mathrm{CN})$; Sự phù hợp của cá nhân đối với tổ chức $(\mathrm{PH})$

\subsection{Tổng kết kết quả kiểm định các giả thuyết}

Kết quả mô hình hồi quy (phương trình 1) cho thấy lòng trung thành của nhân viên tại Công ty TNHH Điện Thành Vinh chịu tác động dương của 8 yếu tố của các thành phần là: CV; LTC; LVN; MT; DT; DN; CN; PH Trong đó, các số 0,$121 ; 0,06 ; 0,133 ; 0,14 ; 0,168 ; 0,115 ; 0,197 ; 0,130$ là các hệ số hồi quy của các biến thành phần ảnh hưởng đến lòng trung thành của nhân viên. Nếu hệ số này càng cao thì mức độ ảnh hưởng của biến thành phần đến lòng trung thành với công ty càng cao.

Bảng 7: Tổng hợp kết quả kiểm định giả thuyết

\begin{tabular}{|c|c|c|}
\hline & Giả thuyết & Kết quả kiểm định \\
\hline $\mathrm{H} 1$ & $\begin{array}{l}\text { Đặc điểm, bản chất công việc ảnh hưởng đến mức độ cam kết } \\
\text { tình cảm của cán bộ nhân viên }\end{array}$ & $\begin{array}{l}\text { Chấp nhận } \\
\text { vì Sig. }=0,000<0.05\end{array}$ \\
\hline $\mathrm{H} 2$ & $\begin{array}{l}\text { Co hội đào tạo và phát triển ảnh hưởng đến mức độ cam kết } \\
\text { tình cảm của cán bộ nhân viên }\end{array}$ & $\begin{array}{l}\text { Chấp nhận } \\
\text { Vì Sig.= } 0,000<0.05\end{array}$ \\
\hline $\mathrm{H} 3$ & $\begin{array}{l}\text { Kỹ năng làm việc theo nhóm ảnh hưởng đến mức độ cam kết } \\
\text { tình cảm của cán bộ nhân viên }\end{array}$ & $\begin{array}{l}\text { Chấp nhận } \\
\text { vì Sig. }=0,000<0.05\end{array}$ \\
\hline $\mathrm{H} 4$ & $\begin{array}{l}\text { Môi trường làm việc ảnh hưởng đến mức độ cam kết tình cảm } \\
\text { của cán bộ nhân viên }\end{array}$ & $\begin{array}{l}\text { Chấp nhận } \\
\text { vì Sig. }=0,000<0.05\end{array}$ \\
\hline H5 & $\begin{array}{l}\text { Quan hệ trong công việc ảnh hưởng đến mức độ cam kết tình } \\
\text { cảm của cán bộ nhân viên }\end{array}$ & $\begin{array}{l}\text { Chấp nhận } \\
\text { vì Sig. }=0,000<0.05\end{array}$ \\
\hline H6 & $\begin{array}{l}\text { Lương, thưởng và chế độ đãi ngộ ảnh hưởng đến mức độ cam } \\
\text { kêt tình cảm của cán bộ nhân viên }\end{array}$ & $\begin{array}{l}\text { Chấp nhận } \\
\text { vì Sig.=0,000<0.05 }\end{array}$ \\
\hline $\mathrm{H7}$ & $\begin{array}{l}\text { Sự công nhận trong công việc ảnh hưởng đến mức độ cam kết } \\
\text { tình cảm của cán bộ nhân viên }\end{array}$ & $\begin{array}{l}\text { Chấp nhận } \\
\text { vì Sig. }=0,000<0.05\end{array}$ \\
\hline $\mathrm{H} 8$ & $\begin{array}{l}\text { Sự phù hợp của cá nhân đối với tổ chức quả ảnh hưởng đến } \\
\text { mức độ cam kết tình cảm của cán bộ nhân viên }\end{array}$ & $\begin{array}{l}\text { Chấp nhận } \\
\text { vì Sig. }=0,000<0.05\end{array}$ \\
\hline
\end{tabular}

\subsection{Thảo luận kết quả nghiên cứu}

Thông qua chỉ số giá trị trung bình của các yếu tố ảnh hưởng đến lòng trung thành của nhân viên tại công ty TNHH Điện Thành Vinh được sắp xếp theo thứ tự giảm dần mức độ ảnh hưởng như sau: Sự công nhận trong công việc $(\mathrm{CN})$; Cơ hội đào tạo và phát triển $(\mathrm{DT})$; Môi trường làm việc $(\mathrm{MT})$; Khả năng làm việc theo nhóm (LVN); Sự phù hợp của cá nhân đối với tổ chức $(\mathrm{PH})$; Đặc điểm, bản chất công việc $(\mathrm{CV})$; Quan hệ trong công việc (DN) và Lương, thưởng và chế độ đãi ngộ (LTC).

Yếu tố Sự công nhận trong công việc $(\mathbf{C N})$ có mức ảnh hưởng mạnh nhất đến lòng trung thành của nhân viên với $\beta=0,197$ so với bảy yếu tố còn lại. Kết quả cho thấy rằng sự công bằng trong khen thưởng, công nhận trong những thành tích công việc có ảnh hưởng tích cực đến lòng trung thành, sự cam kết gắn bó với tổ chức của nhân viên. 
Yếu tố Co hội đào tạo và phát triển (DT) có mức ảnh hưởng mạnh thứ hai đến lòng trung thành của nhân viên với $\beta=0,168$. Kết quả cho rằng tất cả ngành nghề luôn có tốc độ cập nhật và đổi mới rất lớn, điều này khiến cho nhiều nhân viên, nếu không tự cập nhật kiến thức và làm mới chính mình sẽ rất dễ bị lỗi thời, lạc hậu trong tổ chức. Nếu doanh nghiệp không tạo điều kiện cho lập trình viên được học tập và nâng cao trình độ thì sẽ thôi thúc họ muốn kiểm một công việc mới, làm giảm sự trung thành.

Yếu tố Môi trường làm việc (MT) có mức ảnh hưởng mạnh thứ ba đến lòng trung thành của nhân viên với $\beta=0,140$. Kết quả rằng môi trường làm việc tác động tích cực đến lòng trung thành của nhân viên, môi trường làm việc tốt với văn hóa doanh nghiệp tốt tác động tích cực đến lòng trung thành của nhân viên.

Tiếp theo, yếu tố Khả năng làm việc theo nhóm (LVN) có mức ảnh hưởng mạnh thứ tư đến lòng trung thành của nhân viên với $\beta=0,133$. Kết quả cho rằng truyền thông trong tổ chức là sự cởi mở, chia sẻ kiến thức giữa các thành viên trong tổ chức góp phần xây dựng niềm tin trong tổ chức. Truyền thông hiệu quả trong tổ chức trong tổ chức sẽ nhấn mạnh đến sự đồng cảm của nhân viên với tổ chức và xây dựng niềm tin.

Yếu tố Sự phù hợp của cá nhân đối với tổ chức (PH) có mức ảnh hưởng mạnh thứ năm đến lòng trung thành của nhân viên với $\beta=0,130$. Kết quả cho thấy rằng sự phù hợp giữa cá nhân và tổ chức sẽ làm tăng lòng trung thành và sự gắn bó của nhân viên đối với công ty.

Yếu tố Đặc điểm, bản chất công việc $(\mathbf{C V})$ có mức ảnh hưởng mạnh thứ sáu đến lòng trung thành của nhân viên với $\beta=0,121$. Kết cho rằng đặc điểm công việc bao gồm các hoạt động dựa trên nhiệm vụ được giao phó và hoạt động thuộc về tổ chức có tác động đến sự thỏa mãn công việc của nhân viên, từ đó làm tăng lòng trung thành của nhân viên đối với công ty tổ chức, tăng ý định ở lại gắn bó với tổ chức.

Yếu tố Quan hệ trong công việc $(\mathbf{D N})$ với $\beta=0,115$ ảnh hưởng mạnh thứ sáu đến lòng trung thành của nhân viên. Kết quả cho thấy rằng đối với nhân viên thì sự hỗ trợ kịp thời của cấp trên cũng mang lại cho họ sự an tâm trong công việc, phát triển mối quan hệ giữa cấp trên và cấp dưới. Điều này tác động trực tiếp đến lòng trung thành của nhân viên, không chỉ trong ngành cung cấp thiết bị điện.

Yếu tố Lương, thưởng và chế độ đãi ngộ (LTC) có tác động yếu nhất đến lòng trung thành của nhân viên trong tám yếu tố. Với $\beta=0,061$. Kết quả cho thấy chính chế độ đãi ngộ như các hình thức khen thưởng, thăng chức và nhiều quyền lợi khác càng tăng thì lòng trung thành của nhân viên càng tăng và càng làm giảm ý định rời bỏ công việc. Tuy nhiên nhân viên gắn bó với công ty vì nhiều yếu tố khác tác động, lương thưởng và trả công không ảnh hưởng nhiều đến lòng trung thành của nhân viên tại công ty Điện Thành Vinh.

\section{KẾT LUẬN VÀ KIẾN NGH!}

Bằng kỹ thuật phân tích độ tin cậy, phân tích nhân tố khám phá (EFA), và phân tích hồi quy tương quan tuyến tính nhóm tác giả đã xây dựng mô hình nghiên cứu và thang đo đánh giá lòng trung thành nhân viên tại Điện Thành Vinh, theo đó 65\% lòng trung thành nhân viên tại Điện Thành Vinh chịu ảnh hưởng của 8 yếu tố theo mức độ ảnh hưởng giảm dần là: Sự công nhận trong công việc, Cơ hội đào tạo và phát triển, Môi trường làm việc, Khả năng làm việc theo nhóm, Sự phù hợp của cá nhẩn đối với tổ chức, Đặc điểm và bản chất công việc, Quan hệ trong công việc và Lương, thưởng và chế độ đãi ngộ.

Về mặt đề xuất kiến nghị, nghiên cứu đã đề xuất cho ban giám đốc công ty Điện Thành Vinh các giải pháp nhằm nâng cao lòng trung thành của nhân viên tại Điện Thành Vinh:

Về Sự công nhận trong công việc : Kết quả nghiên cứu cho thấy, sự công nhận trong công việc là yếu tố có ảnh hưởng mạnh nhất đến lòng trung thành của nhân viên $(\beta=0,197)$. Cấp trên tạo mối quan hệ gần gũi với nhân viên, ghi nhận những đóng góp của nhân viên đánh giá năng lực của họ giúp họ thăng tiến theo đúng quy định mà công ty đề ra. Phản hồi về công việc một cách chính xác, kịp thời cho nhân viên để họ có thể biết được điều gì tốt và chưa tốt để họ có thể điều chỉnh. Lãnh đạo cần đối xử công bằng với mọi nhân viên không nên để vấn đề tình cảm xen lẫn vào các quyết định của công việc như đánh giá kết quả thực hiện công việc và cơ hội thăng tiến. Có như vậy giúp cho nhân viên có được niền tin vào sự công bằng của cấp trên mà cố gắng phấn đấu.

Về Co hội đào tạo và phát triển : Công ty nên tạo cơ hội thăng tiến công bằng cho mỗi cá nhân bằng cách xây dựng hệ thống đánh giá hiệu quả công việc được giao theo định kỳ một quý một lần, hoặc theo năm nhằm xác định hiệu quả công việc một cách chính xác. Ghi nhận kết quả đó và có những phần thưởng xứng đáng cho những nhân viên đạt thành tích cao. Minh bạch con đường thăng tiến vì đó chính là khát vọng của mỗi nhân viên qua đó chứng minh được khả năng, hiệu quả làm việc của họ. Bên cạnh đó, việc đào tạo hiện 
nay còn nhiều hạn chế như khả năng bố trí người thay thế công việc. Chưa chọn đúng đối tượng đào tạo. Các khóa học phải gắn liền với thực tế, huấn luyện nghiệp vụ cơ bản giúp họ có thể hòa nhập nhanh với môi trường làm việc.

Về Môi trường làm việc : Công ty cần chú trọng trong công tác trang bị tài liệu phục vụ cần thiết cho công việc như sách hướng dẫn, ấn phẩm nhằm giúp cán bộ công nhân viên có thể nâng cao trình độ chuyên môn, các hướng dẫn chi tiết để hòa nhập tốt với doanh nghiệp.Tạo môi trường làm việc thoải mái với văn hóa doanh nghiệp tốt, môi trường không khí thân thiện cởi mở, giúp đỡ và chia sẻ trong công việc với nhau sẽ giúp nhân viên thực hiện công việc trong tâm thế thoải mái nhất và yêu môi trường làm việc của mình.

Về khả năng làm việc theo nhóm : Công ty cần xây dựng các khóa học ngoại khóa, tổ chức họp mặt cuối năm,... cho nhân viên thuộc các phòng ban, các bộ phận để tạo điều kiện giao lưu trao đổi kiến thức, kinh nghiệm với nhau. Tổ chức học tập và làm việc theo đội nhóm thi đua với nhau nhằm tạo sự gắn kết giữa nhân viên với nhau, hỗ trợ giúp đỡ nhau hoàn tất công việc tốt hơn

Về Sự phù hợp của cá nhân đối với tổ chức: Công ty cần xây dựng dạng văn hóa đổi mới và văn hoá hỗ trợ. Văn hoá đồi mới: nhân viên định hướng theo công việc; lãnh đạo khyến khích sự đổi mới; tổ chức tạo hào hứng cho mọi người; tạo thách thức trong công việc; lãnh đạo khuyến khích nhân viên đưa ra các chủ đề chung; chấp nhận những sai lầm của nhân viên để rút kinh nghiệm. Văn hoá hỗ trợ: tổ chức định hướng hoạt động vào các mối quan hệ; khuyến khích, động viên các thành viên; chú trọng tự do cá nhân; chú trọng bình đẳng; cởi mở, chia sẻ và giúp đỡ; quan tâm các hoạt động tập thể; có sự liên kết giữa các phòng ban, bộ phận.

Về Đặc điểm, bản chất công việc: Satra nên xây dựng quy trình đánh giá kết quả làm việc cụ thể, rõ ràng và công bằng nhằm giúp ích cho nhân viên nâng cao chất lượng công việc, nhằm có kết hoạch đào tạo và phát triển nghề nghiệp của mỗi nhân viên và được lãnh đạo phản hồi tích cực mức độ hoàn thành công việc. Việc thực hiện đánh giá và mô tả tính chất công việc chính xác rõ ràng sẽ làm cho người lao động cam kết gắn bó với công ty ngày càng cao.

Về Quan hệ trong công việc: Điện Thành Vinh cần quan tâm hơn đến khía cạnh chia sẻ thông tin nội bộ để tất cả mọi người có thể chia sẻ thông tin và cập nhật tin tức nội bộ một cách nhanh nhất. Bên cạnh đó thường xuyên tổ chức những ngày hội văn hóa, dịp nghỉ mát các buổi sinh hoạt tập thể để các nhân viên có cơ hội giao lưu, thắt chặt tình đồng nghiệp.

Về Lương, thưởng và chế độ đãi ngộ: Đảm bảo việc phân phối thu nhập được công bằng, công ty cần có chính sách lương, thưởng rõ ràng dựa vào đánh giá khách quan và công bằng năng lực, hiệu quả công việc của nhân viên. Sự công bằng phụ thuộc rất nhiều vào nhận thức của người lao động nên cần tìm cách giúp nhân viên nhận thức rằng họ được trả thu nhập một cách công bằng. Đưa ra nhiều chương trình thi đua và những phần thưởng hấp dẫn dành cho những nhân viên xuất sắc thuộc các bộ phân trong công ty. Phần thưởng có thể là vật chất hoặc tinh thần như: bằng khen, quà tặng của công ty,...

\section{TÀI LIỆU THAM KHẢO}

\section{Danh mục tài liệu Tiếng Việt}

[1] Lê Cảnh Phước (2007), "Khảo sát các yếu tố ảnh hưởng đến lòng trunh thành của nhân viên đối với doanh nghiệp."

[2] Nguyễn Thị Phương Dung (2012), "Xây dựng thang đo động viên nhân viên khối văn phòng ở Thành phố Cần

Thơ”, Tạp chí Khoa học 2012:22b 145-154, ĐH Cần Thơ.

[3] Nguyễn Thanh Hội (2007), Quản trị học, Nhà Xuất bản Thống kê.

[4] Phan Văn Kha (2007), Đào tạo và sủ dụng nhân lực trong nền kinh tế thị truờng ở Việt Nam, Nhà Xuất bản Giáo dục.

[5] Trần Kim Dung (2005), "Đo lường mức độ thỏa mãn đối với điều kiện công việc trong điều kiện Việt Nam". Tạp chí Phát triển Khoa học Công Nghệ. ĐH Quốc Gia Tp. HCM.

[6] Trần Kim Dung (2011), Quản trị nguồn nhân lục, Nhà Xuất bản Thống kê.

[7] Trần Thái Hòa (2014), "Biện pháp nâng cao lòng trung thành của nhân viên tại công ty TNHH kiểm toán và dịch vụ tin học thành phố Hồ Chí Minh.” 
[8] Trần Thị Cẩm Thúy (2011), “Ảnh hưởng của lãnh đạo tạo sự thay đổi đến sự thỏa mãn với công việc và lòng trung thành đối với tổ chức của nhân viên."

\section{Danh mục tài liệu tiếng Anh}

[1] Meyer, J. P.; Allen, N. J. (1991). "A three-component conceptualization of organizational commitment". Human Resource Management Review

[2] Mowday, Steers, Poter (1979), "Organizational commitment, job satisfaction, and turnover among psychiatric technicians."

[3] Magid Igbaria, Guy Meredith, Derek C. Smith (1994), "Predictors of intention of IS professionals to stay with the organization in South Africa."

[4] Thomas S. Bateman, Stephen Strasser (1984) "A Longitudinal Analysis of the Antecedents of Organizational Commitment"

[5] Janet Chew (2014), "The influence of human resource management practices on the retention of core employees of Australian organisations: an empirical study."

[6] Jen-Ruei Fu, Jessica H.F. Chen (2015), "Career commitment of information technology professionals: The investment model perspective."

[7] Sayyed Muhammad Mehdi Raza Naqvi, Sajid Bashir (2008), "IT-expert retention through organizational commitment: A study of public sector information technology professionals in Pakistan."

Ngày nhận bài: 06/01/2020

Ngày chấp nhận đăng: 25/03/2020 